\title{
Transmucosal Fine Needle Aspiration of Oral and Pharyngeal Lesions
}

\author{
Fang-Ming Deng, ${ }^{1}$ Jack Hsu, ${ }^{2}$ and Kamal K. Khurana ${ }^{1}$ \\ ${ }^{1}$ Department of Pathology, State University of New York, Upstate Medical University, 750 East Adams Street, \\ Syracuse, NY 13210, USA \\ ${ }^{2}$ Department of Otolaryngology, State University of New York, Upstate Medical University, 750 East Adams Street, \\ Syracuse, NY 13210, USA \\ Correspondence should be addressed to Kamal K. Khurana, khuranak@upstate.edu
}

Received 21 March 2011; Accepted 24 April 2011

Academic Editor: J. A. Jimenez-Heffernan

Copyright (๑) 2011 Fang-Ming Deng et al. This is an open access article distributed under the Creative Commons Attribution License, which permits unrestricted use, distribution, and reproduction in any medium, provided the original work is properly cited.

Fine Needle aspiration (FNA) studies of oropharyngeal lesions are few and limited. We retrospectively reviewed cytologic diagnosis and cytohistologic correlation of 28 cases of FNAs of oropharyngeal lesions. Cytologically, 11 cases were diagnosed as malignant/suspicious and 17 cases as benign. Ten of these cases diagnosed as malignant/suspicious correlated with the subsequent histological diagnosis or were compatible with previous histological diagnoses. One case categorized as suspicious for malignancy revealed pleomorphic adenoma with extensive squamous metaplasia. Of the 17 cases diagnosed as benign by cytology, 11 correlated with the subsequent histological diagnosis. The remaining 6 cytologically benign cases were considered clinically benign, and there was no histological followup. Clinical followup on these 6 patients did not reveal any evidence of disease. The sensitivity, specificity, and accuracy of malignant diagnosis were 100\%, 95\%, and 97\%. FNA biopsy may be used as the first line of investigation in evaluation of oropharyngeal lesions.

\section{Introduction}

Superficial or image-guided fine needle aspiration (FNA) biopsy has been used extensively in superficial and various deep-seated tissues. It is simple, safe, economical, and proven to have high sensitivity and specificity. It is minimally invasive and well-tolerated by the patients, so that repeat sampling may be performed if required. The use of quick staining methods allows a rapid provisional diagnosis to be achieved in most cases, guiding further management $[1,2]$. There are a wide variety of benign or malignant neoplasms originating from the squamous mucosa, salivary glands, mesenchymal structures, and lymphoid tissues within the oral cavity and oropharynx, in addition to inflammation and benign cysts. These lesions are traditionally evaluated by surgical biopsy, and transmucosal needle aspiration studies of oral cavity and pharyngeal lesions are few and limited [39]. The oral cavity and oropharynx are readily accessible to FNA biopsy. FNA biopsy may be as good as or better than surgical biopsy in the preliminary assessment and definitive pathological diagnosis of submucosal oral or pharyngeal lesions.

Here, we present our experience with FNA cases of oral and oropharyngeal lesions performed in our institution, with particular attention to cytologic features of specific tumors, diagnostic accuracy, and cytohistologic correlation.

\section{Material and Methods}

2.1. Patient Demographics. A search of the cytology files of the Department of Pathology at SUNY Upstate Medical University, Syracuse, NY USA between January 1996 and February 2009 was conducted. Twenty-eight patients with oral cavity or pharyngeal lesions underwent transoral FNA at our institution. We retrospectively reviewed the cytologic and the histologic diagnosis and the clinical followup when indicated. 
2.2. Fine Needle Aspiration and Histology Study. All FNA procedures were performed by pathologists. In most of the cases, we did not use any anesthesia during the FNA procedure. A local ethyl chloride spray was applied in a few selected patients. All FNAs were performed using 25- or 23gauge $(0.25$ or $0.23 \mathrm{~mm})$ needles attached to $20-\mathrm{ml}$ syringe in a cameco aspiration device [6]. In some cases, resident assistant used tongue depressor to enable better visualization of the lesion. Similar maneuvers were used in children less than 6 years old. However, procedure was performed under sedation administered by the anesthesiologist. No compression was needed after the procedure other than that provided by natural closing of the mouth.

In all the cases, the material obtained was smeared onto uncoated glass slides and either air-dried or fixed in ethanol for Diff Quick or Papanicolaou stain, respectively. During the procedure, each specimen was checked for adequacy; as soon as diagnostic material was secured, the procedure was discontinued. The material procured for a cell block was fixed in $10 \%$ neutral-buffered formalin, embedded in paraffin, sectioned at $4 \mu \mathrm{m}$ and stained with hematoxylin and eosin. The latter methods were also applied to the histologic samples.

\section{Results}

Table 1 provides the summary of cases in the current study including the cytologic and final histologic diagnosis or clinical followup. The age of the patients ranged from 3 to 91 years (mean 50), with 17 males and 11 females. The biopsy sites included cheek (6), hard and soft palate (9), floor of mouth (2), mandible (1), and pharynx (10).

Cytologically, 11 patients (cases 18-28) were diagnosed as malignant/suspicious and 17 were diagnosed as benign. Cases with a diagnosis of malignant/suspicious, included: squamous cell carcinoma $(n=2)$, adenoid cystic carcinoma $(n=2)$, polymorphous low-grade adenocarcinoma $(n=2)$, lymphoma $(n=1)$, chondrosarcoma $(n=1)$, metastatic adenocarcinoma $(n=1)$, metastatic poorly differentiated carcinoma $(n=1)$, and pleomorphic adenoma with squamous metaplasia $(n=1)$.

Of the 11 malignant/suspicious cases, 10 cases correlated with the histologic diagnosis (8 cases correlated with subsequent histological diagnosis, and 2 cases of metastatic tumor were compatible with previous histological diagnosis. Flow cytometry enabled a correct diagnosis of B-cell lymphoma on one of the cytologic samples. One case diagnosed as atypical squamous cell proliferation, cannot exclude squamous cell carcinoma by cytology, was later diagnosed as pleomorphic adenoma with extensive squamous metaplasia by histology.

Cases with cytologic diagnosis of benign (Cases 1-17) included benign neoplasms $(n=4)$, inflammatory lesions $(n$ $=5)$ and cyst $(n=4)$ and negative for malignancy/descriptive $(n=4)$. Four benign neoplasms included: pleomorphic adenoma $(n=3)$ and Warthin's tumors $(n=1)$. Of the 17 benign cases, 11 cases (including 4 cases of tumor) correlated with the histologic diagnosis. Six cases were considered clinically benign and did not require histological followup; however, clinical followup (2-3 years) showed no evidence of malignancy.

\subsection{Pathologic Findings}

3.1.1. Squamous Cell Carcinoma. Smears from cases with cytologic diagnoses of squamous cell carcinoma were cellular and had solid sheets of neoplastic cells. Individual cells had dense keratinized cytoplasm, marked nuclear pleomorphism, occasional prominent nucleoli, nuclear hyperchromasia, and irregular nuclear membranes. Necrotic debris and inflammatory background were also identified in 3 cases. Cell block preparation revealed sheets of malignant squamous cells with similar cytologic features.

3.1.2. Adenoid Cystic Carcinoma. Aspirate smears revealed metachromatic hyaline globules and small basaloid uniform tumor cells with minimal cytoplasm forming clusters and glands. Occasional single cells were also seen (Figures 1(a) and $1(\mathrm{~b}))$.

3.1.3. Polymorphous Low-grade Adenocarcinoma. The FNA smears revealed uniform small blue tumor cells (basaloid cells) with uniform round to oval nuclei with granular chromatin: inconspicuous nucleoli and scant to moderate cytoplasm (Figures 2(a) and 2(b)).

3.1.4. Chondrosarcoma. The FNA smears comprised of abundant hypercellular chondroid material with many atypical binucleated and occasional trinucleated cells. Follow-up histopathology confirmed the diagnosis of chondrosarcoma (Figures 3(a) and 3(b)).

3.1.5. Lymphoma. The FNA smears showed a monotonous population of large lymphoid cells. Flow cytometry and histologic findings were consistent with Follicular B-cell lymphoma.

\subsubsection{Metastatic Adenocarcinoma and Poorly Differentiated} Carcinoma. The aspirate smears consisted of tumor cells with moderate to abundant cytoplasm, increased nuclear cytoplasmic ratio, overlapping and hyperchromatic nuclei, and increased mitotic figures. Glandular configuration was prominent in case of metastatic adenocarcinoma. Cytologic features of tumor were compatible with those of previously resected primary tumors of head and neck.

3.1.7. Pleomorphic Adenoma with Extensive Squamous Metaplasia. The FNA smears revealed predominantly squamous cells with some nuclear atypia. No chondromyxoid stroma or hyaline cells were identified. Histologic followup revealed pleomorphic adenoma with squamous metaplasia with reactive changes (Figures 4(a) and 4(b)).

3.1.8. Pleomorphic Adenoma. The FNA smears revealed chondromyxoid stroma admixed with hyaline cells and mesenchymal cells. Histologic followup confirmed the cytologic diagnosis (Figures 5(a) and 5(b)). 
TABle 1: Patient Demographics and Pathological Diagnosis.

\begin{tabular}{|c|c|c|c|c|c|}
\hline Case number & Age & Sex & Site & Cytologic diagnosis & Histologic diagnosis \\
\hline 1 & 38 & $\mathrm{M}$ & Soft palate & $\begin{array}{l}\text { Mixed microbial infection with } \\
\text { necrosis }\end{array}$ & NA \\
\hline 2 & 51 & M & Oropharynx & Abscess & $\begin{array}{l}\text { Granulation tissue with acute and } \\
\text { chronic inflammation }\end{array}$ \\
\hline 3 & 4 & $\mathrm{M}$ & Cheek & Acute and chronic inflammation & Mixed microbial infection with necrosis \\
\hline 4 & 44 & $\mathrm{M}$ & R mandibular & $\begin{array}{c}\text { Marked } \\
\text { Acute inflammation and granulation } \\
\text { tissue }\end{array}$ & NA \\
\hline 5 & 3 & M & L cheek & CI, NEM & Chronic inflammation \\
\hline 6 & 23 & $\mathrm{~F}$ & L retropharyngeal & Benign squamous-lined cyst & Branchial cleft cyst \\
\hline 7 & 70 & $\mathrm{M}$ & $\mathrm{R}$ maxillary sinus & NEM, c/w cyst & Chronic inflammation and fibrosis \\
\hline 8 & 15 & M & Floor of mouth & NEM, c/w cyst & NA \\
\hline 9 & 24 & $\mathrm{M}$ & Hard palate & NEM, c/w cyst & Nasopalatine cyst \\
\hline 10 & 35 & $\mathrm{M}$ & Tonsil & Benign squamous cells & NA \\
\hline 11 & 50 & $\mathrm{~F}$ & L cheek & NEM & NSPC \\
\hline 12 & 42 & $\mathrm{~F}$ & R floor of mouth & NEM & NA \\
\hline 13 & 41 & M & L cheek & NEM & NA \\
\hline 14 & 75 & M & R parapharyngeal & $\begin{array}{l}\text { Oncocytic lesion, c/w Warthin's } \\
\text { tumor }\end{array}$ & Warthin's tumor \\
\hline 15 & 51 & M & Midline hard palate & $\mathrm{PA}$ & $\mathrm{PA}$ \\
\hline 16 & 23 & M & $\mathrm{R}$ parapharyngeal & $\mathrm{PA}$ & $\mathrm{PA}$ \\
\hline 17 & 61 & $\mathrm{~F}$ & R palate & $\mathrm{PA}$ & $\mathrm{PA}$ \\
\hline 18 & 58 & $\mathrm{M}$ & R palate & Atypical squamous proliferation & PA with extensive squamous metaplasia \\
\hline 19 & 91 & $\mathrm{~F}$ & R cheek & SCC & Invasive SCC \\
\hline 20 & 44 & $\mathrm{~F}$ & L pharaynx & SCC & Invasive SCC \\
\hline 21 & 73 & $\mathrm{M}$ & L hard palate & Adenoid cystic carcinoma & Adenoid cystic carcinoma \\
\hline 22 & 56 & M & $\mathrm{R}$ upper palate & Poorly differentiated carcinoma & High-grade adenoid cystic carcinoma \\
\hline 23 & 43 & $\mathrm{~F}$ & L palate & Basaloid neoplasm & PLGA \\
\hline 24 & 48 & $\mathrm{~F}$ & L palate & Basaloid neoplasm & PLGA \\
\hline 25 & 63 & $\mathrm{~F}$ & $\mathrm{R}$ hard palate & c/w B cell lymphoma* & Follicular lymphoma \\
\hline 26 & 76 & M & Larynx & c/w chondrosarcoma & Low-grade chondrosarcoma \\
\hline 27 & 62 & $\mathrm{~F}$ & L retropharyngeal & $\begin{array}{l}\text { Metastatic poorly differentiated } \\
\text { carcinoma }\end{array}$ & $\begin{array}{l}\text { Correlated with prior head and neck } \\
\text { primary resection }\end{array}$ \\
\hline 28 & 60 & $\mathrm{M}$ & R cheek & Metastatic adenocarcinoma & $\begin{array}{l}\text { Correlated with prior head and neck } \\
\text { primary resection }\end{array}$ \\
\hline
\end{tabular}

* Flow cytometry study performed. C/w: consistent with; L: left; NEM: No evidence of malignancy; NSPC: no significant pathologic changes; PA: pleomorphic adenoma; PLGA: polymorphous low-grade adenocarcinoma; R: right; SCC: squamous cell carcinoma. NA: no histologic followup available/case followed clinically.

3.1.9. Warthin's Tumor. Aspirate smears revealed sheets and clusters of oncocytes and scattered lymphocytes. Cell block showed oncocytic epithelium with a lymphocyte rich stroma. Follow-up histology confirmed the diagnosis of Warthin's tumor (Figures 6(a) and 6(b)).

3.1.10. Other Benign Lesions. Cytologic findings in cases of cysts revealed histiocytes and benign epithelial cells or squamous cells. Although possibility of contamination from normal oral cavity cannot be excluded in presence of benign squamous cells, identification of histiocytes confirms the cystic nature of the lesion. Inflammatory lesions were characterized by acute or chronic inflammation. In four cases with no cytologic evidence of malignancy, benign squamous cells, adipose tissue, and minor salivary glands were noted. In cases where histologic followup was not available, clinical followup showed regression of these swellings.

The overall diagnostic accuracy of transmucosal FNA for oral and pharyngeal lesions was $96.6 \%$. The sensitivity, specificity, and accuracy of malignant diagnosis were $100 \%$, $95 \%$, and $97 \%$.

\section{Discussion}

FNA is a quick, minimally invasive procedure that can be performed in an outpatient setting with few complications. 


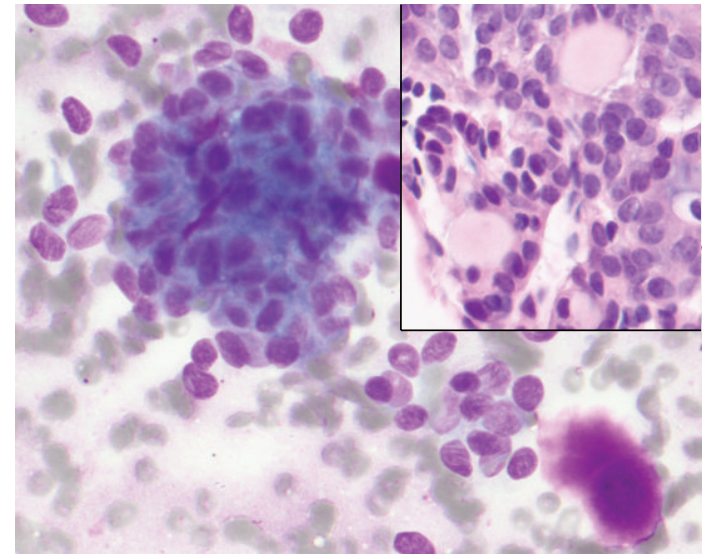

(a)

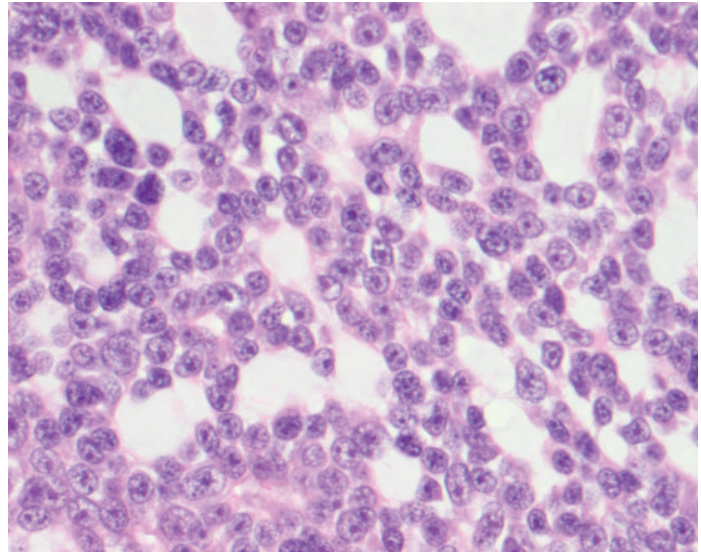

(b)

Figure 1: (a) Basaloid cells with mild to moderate pleomorphism and hyaline matrix spheres (Diff Quick stain $\times 200$ ). Cell block neoplastic glands in a cribriform pattern (insert: $\mathrm{H} \& \mathrm{E}$ stain $\times 200$ ). (b) Follow-up histopathology confirmed the diagnosis of adenoid cystic carcinoma (H \& E stain $\times 200)$.

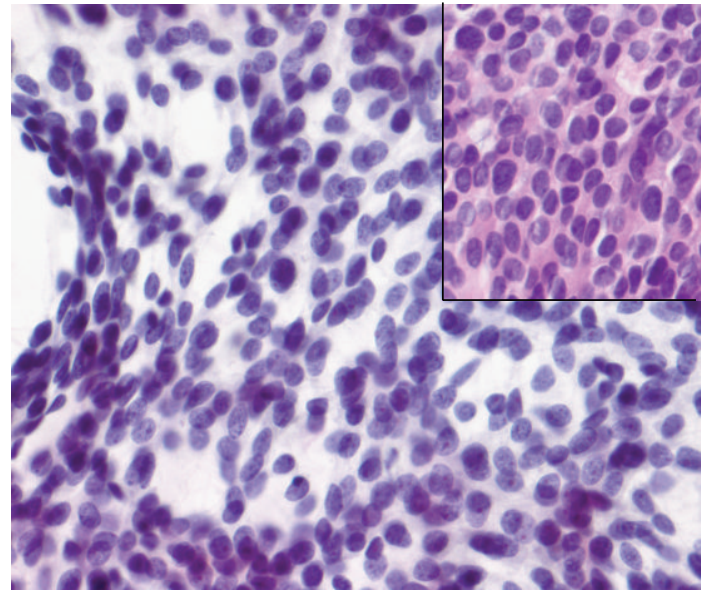

(a)

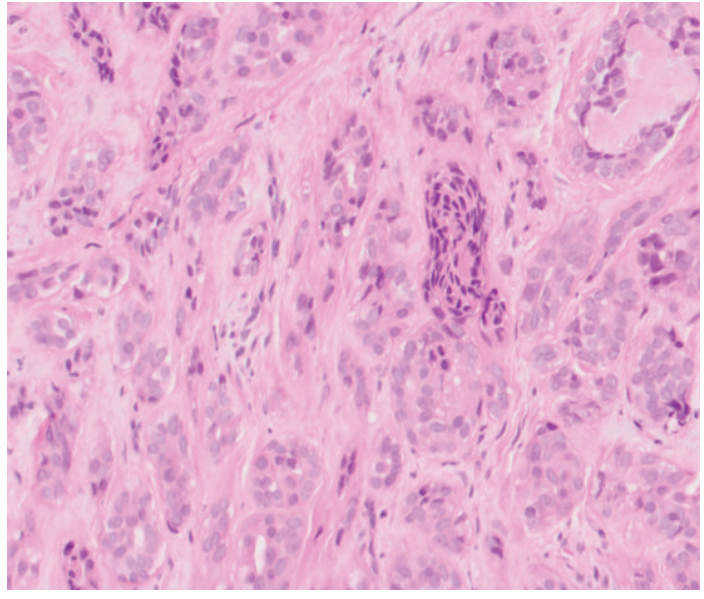

(b)

Figure 2: (a) Sheets and single basaloid cells with mild pleomorphism (Diff Quick stain $\times 200$ ). Cell block showed similar features (insert, $\mathrm{H} \& \mathrm{E}$ stain $\times 200$ ). (b) Follow-up histopathology showed polymorphous low-grade adenocarcinoma $(\mathrm{H} \& \mathrm{E}$ stain $\times 200)$.

It has gained popularity in the initial diagnostic investigation of masses in the head and neck regions.

Currently, the bulk of literature on intraoral lesions is based on surgical specimens with much less reported on FNA diagnosis of these lesions [3-9]. This may be due to patient anxiety, discomfort, and difficulty in localizing these lesions during the procedure. In our series, the lesions were well localized, and FNA enabled us to obtain sufficient material in all cases after 1-3 passes. Patient discomfort, including mild pain and gag reflex was minimal. We did not encounter any significant complications.

The main goal of this study was to determine the usefulness of intraoral FNA in accurately diagnosing lesions and to correlate with histologic diagnosis or clinical followup. Of the 28 cases in our series, there was only one false positive case, and the remaining cases were accurately classified as benign versus malignant/suspicious. The false positive case was of pleomorphic adenoma with extensive squamous metaplasia. The aspirate smears and cell block in this case showed mature single cells and clusters of squamous epithelial cells with nuclear atypia making it difficult to differentiate reactive squamous cells with atypia from squamous cell carcinoma. Follow-up histopathology showing pleomorphic adenoma with extensive squamous metaplasia. Only a few areas showed classic pleomorphic adenoma features were identified. Retrospective review of cytological smears did not find any area suggestive of pleomorphic adenoma. The atypical squamous cells represented reactive changes involving areas of squamous metaplasia. The cytologic discrepancy in this case may be attributed to limitation of sampling and cytologic interpretation of squamous atypia. Squamous metaplasia in benign salivary 




(a)

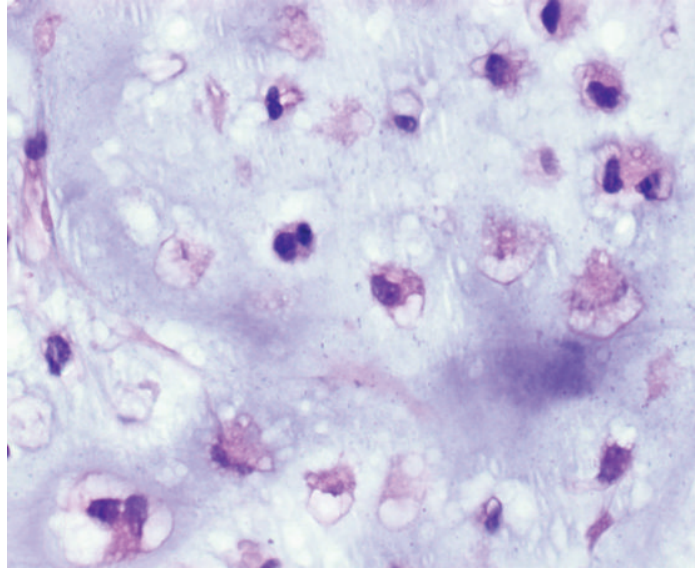

(b)

Figure 3: (a) Abundant hypercellular chondroid material (Diff Quick stain $\times 200$ ) with many binucleated and occasional trinucleated cells (insert, Pap stain $\times 200$ ). (b) Follow-up histopathology confirmed the diagnosis of chondrosarcoma $(\mathrm{H} \& \mathrm{E}$ stain $\times 200)$.

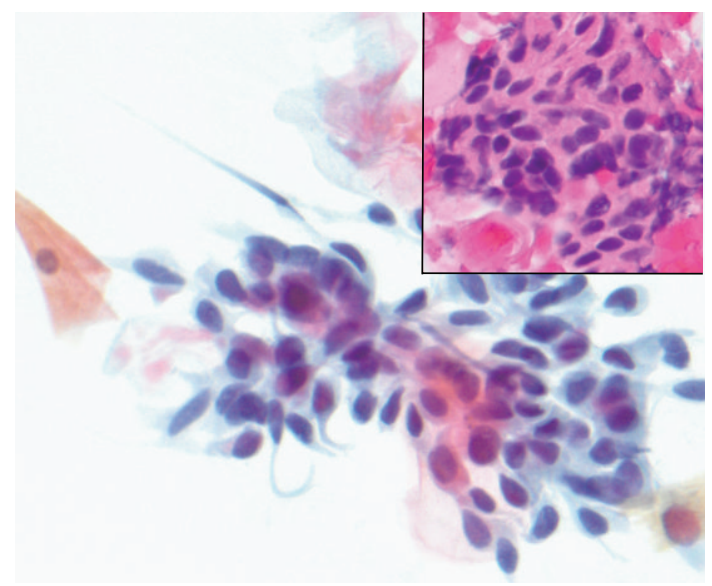

(a)

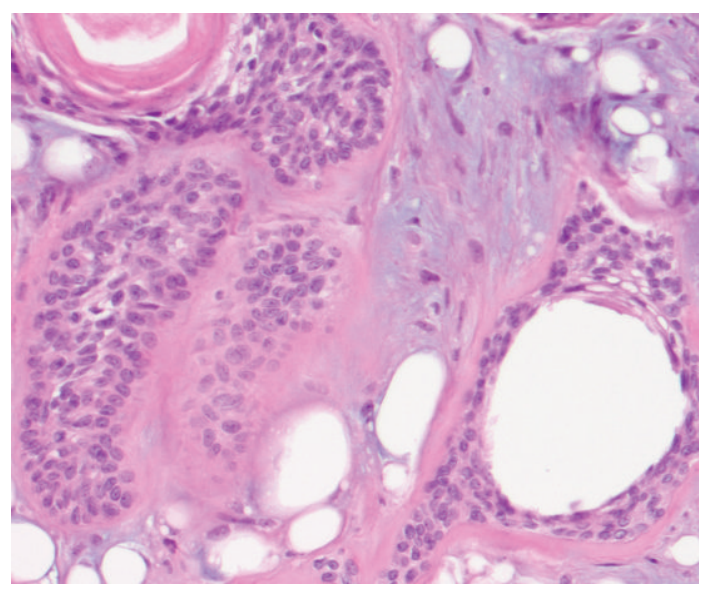

(b)

Figure 4: (a) Mature single and clusters of squamous epithelial cells with occasional enlarged atypical cells (Pap stain $\times 200$ ). The cell block showed similar features (insert, H \& E stain $\times 200$ ). (b) Follow-up histopathology showed pleomorphic adenoma with extensive squamous metaplasia (H \& E stain $\times 200)$.

gland tumor as a source of potential diagnostic pitfall has been previously reported [10]. Hence, caution is warranted in interpretation of such tumors.

Two other cases that were accurately classified as suspicious for malignancy were diagnosed as basaloid tumors and were actually cases of polymorphous low-grade adenocarcinoma. These tumors were characterized by proliferation of small uniform, hyperchromatic, basaloid tumor cells with minimal cytoplasm. In addition to the possibility of lowgrade polymorphous adenocarcinoma in these cases, differential diagnosis may also include adenoid cystic carcinoma, basal cell adenoma/carcinoma, lymphoma and metastatic basaloid squamous cell carcinoma, or nasopharyngeal carcinoma [11-13]. The cytologic findings alone in these cases raise several diagnostic possibilities. Although careful review of clinical history including prior history of malignancy may enable a correct diagnosis in few of these cases, additional excisional biopsy as performed in these cases may be necessary to delineate these lesions further.

Specific diagnosis correlated with all cases with histologic followup except 3 cases in suspicious category as discussed above. In most instances, it is possible to make a specific diagnosis. This is very helpful in patients for surgical or conservative management which may help avoid unnecessary surgery or allow for quicker treatment. FNA is also helpful in distinguishing lymphoma from lymphoid hyperplasia using additional material for flow cytometry as performed in one of our cases. Other molecular studies may also be performed if there is a suspicion for lymphoma.

In our series, sensitivity, specificity, and accuracy of $100 \%, 95 \%$, and 97\%, respectively, of intraoral FNA are comparable to that of previously reported series $[4,7,8]$. The diagnosis is usually easy or straightforward for nonneoplastic lesions, including inflammation and benign cysts. 


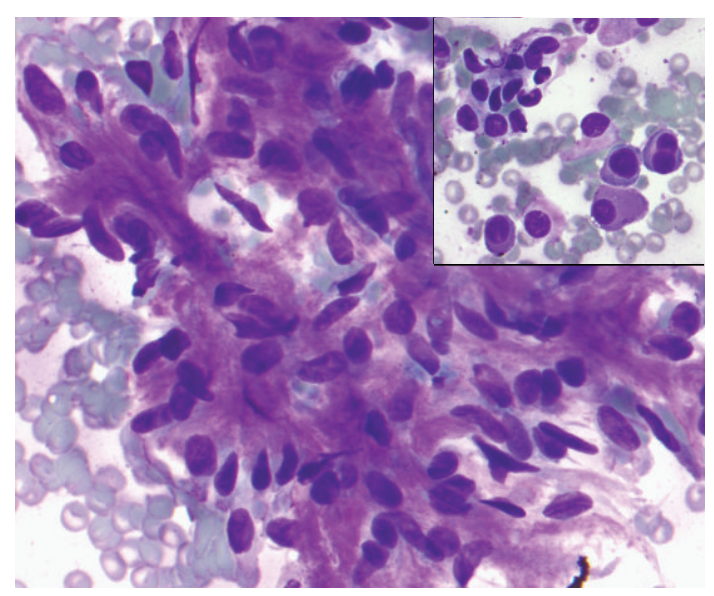

(a)

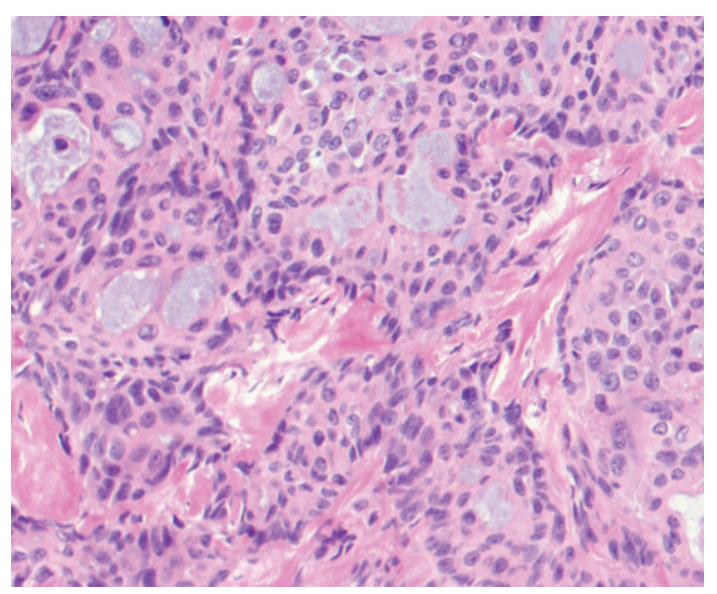

(b)

Figure 5: (a) Bland epithelial cells, some with plasmacytoid appearance (Diff Quick stain $\times 200$ ) intermixed with a chondromyxoid stroma (insert, Diff Quick stain $\times 200$ ). (b) Follow-up histopathology confirmed the diagnosis of pleomorphic adenoma $(\mathrm{H} \& \mathrm{E}$ stain $\times 200)$.

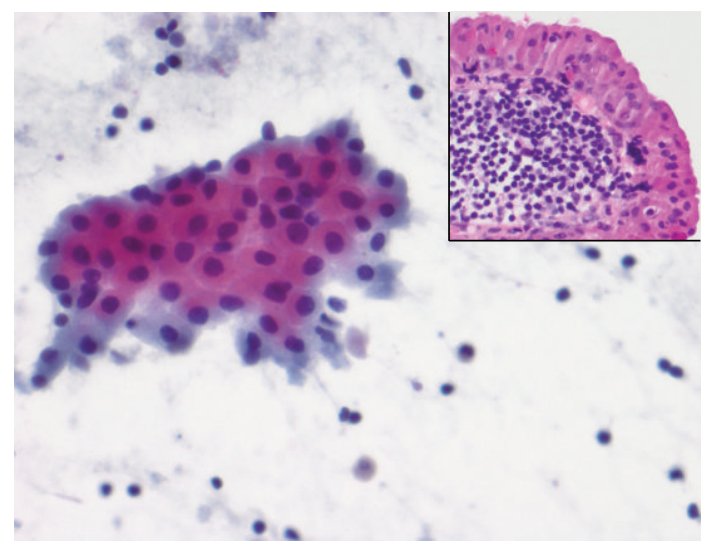

(a)

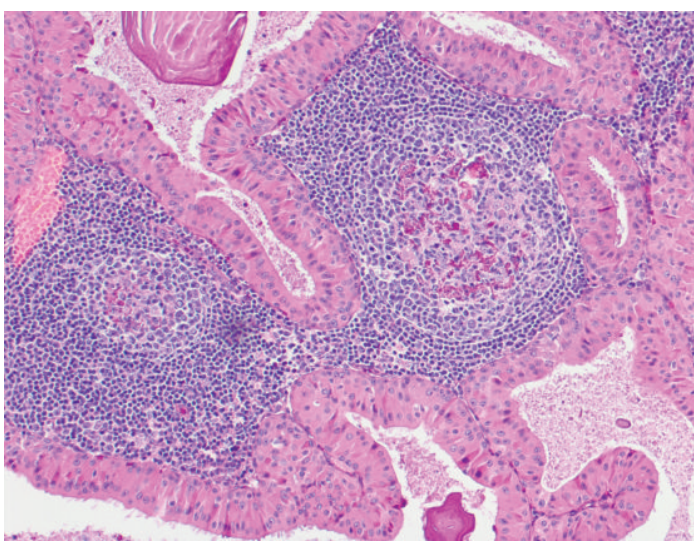

(b)

Figure 6: (a) Bland oncocytic cells in a background of lymphocytes (Pap stain $\times 200$ ). The cell block showed oncocytic epithelium with a lymphocyte-rich stroma (insert, H \& E stain $\times 200$ ). (b) Follow-up histology confirmed the diagnosis of Warthin's tumor $(\mathrm{H} \& \mathrm{E}$ stain $\times 200)$.

In summary, transmucosal FNA biopsy permits rapid and accurate diagnosis of both benign and malignant lesions of the oral cavity and pharynx. It is easy to do, well tolerated by patients, and has few, minor complications. It may be used as the first line of investigation in evaluation of oral and pharyngeal lesions.

\section{Acknowledgment}

This paper was presented in part in poster form at the 57th Annual Scientific Meeting of American Society of Cytopathology held in Denver Colorado in November 2009.

\section{References}

[1] C. J. Stewart, K. MacKenzie, G. W. McGarry, and A. Mowat, "Fine-needle aspiration cytology of salivary gland: a review of
341 cases," Diagnostic Cytopathology, vol. 22, no. 3, pp. 139146, 2000.

[2] R. Bardales, S. J. Baker, and P. Mukunyadzi, "Fine-needle aspiration cytology findings in 214 cases of nonparotid lesions of the head," Diagnostic Cytopathology, vol. 22, no. 4, pp. 211217, 2000.

[3] R. L. Scher, P. E. Oostingh, P. A. Levine, R. W. Cantrell, and P. S. Feldman, "Role of fine needle aspiration in the diagnosis of lesions of the oral cavity, oropharynx, and nasopharynx," Cancer, vol. 62, no. 12, pp. 2602-2606, 1988.

[4] M. Castelli, P. Gattuso, C. Reyes, and E. P. Solans, "Fine needle aspiration biopsy of intraoral and pharyngeal lesions," Acta Cytologica, vol. 37, no. 4, pp. 448-450, 1993.

[5] H. Cramer, H. Lamper, and P. Downing, "Intraoral and transoral fine needle aspiration. A review of 25 cases," Acta Cytologica, vol. 39, no. 4, pp. 683-688, 1995.

[6] H. Domanski and M. Akerman, "Fine-needle aspiration cytology of tongue swellings: a study of 75 cases," Diagnostic Cytopathology, vol. 18, no. 6, pp. 387-392, 1998. 
[7] S. B. Shah, M. I. Singer, E. Liberman, and B. M. Ljung, "Transmucosal fine-needle aspiration diagnosis of intraoral and intrapharyngeal lesions," Laryngoscope, vol. 109, no. 8, pp. 1232-1237, 1999.

[8] H. A. Saleh, L. Clayman, and H. Masri, "Fine needle aspiration biopsy of intraoral and oropharyngeal mass lesions," CytoJournal, vol. 5, Article ID 4, 2008.

[9] B. R. Oliai, S. Sheth, F. H. Burroughs, and S. Z. Ali, "“Parapharyngeal space" tumors: a cytopathological study of 24 cases on fine-needle aspiration," Diagnostic Cytopathology, vol. 32, no. 1, pp. 11-15, 2005.

[10] C. C. Su, C. W. Chou, and C. Y. Yiu, "Neck mass with marked squamous metaplasia: a diagnostic pitfall in aspiration cytology," Journal of Oral Pathology and Medicine, vol. 37, no. 1, pp. 56-58, 2008.

[11] M. W. Stanley, "Selected problems in fine needle aspiration of head and neck masses," Modern Pathology, vol. 15, no. 3, pp. 342-350, 2002.

[12] M. W. Stanley, C. A. Horwitz, R. H. Bardales, S. J. Stern, and S. Korourian, "Basal cell carcinoma metastatic to the salivary glands: differential diagnosis in fine-needle aspiration cytology," Diagnostic Cytopathology, vol. 16, no. 3, pp. 247252, 1997.

[13] D. Gibbons, M. H. Saboorian, F. Vuitch, S. T. Gokaslan, and R. Ashfaq, "Fine-needle aspiration findings in patients with polymorphous low grade adenocarcinoma of the salivary glands," Cancer, vol. 87, no. 1, pp. 31-36, 1999. 


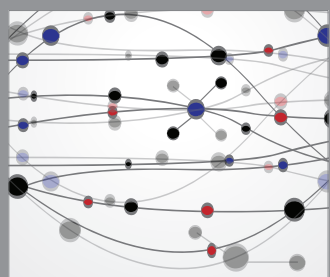

The Scientific World Journal
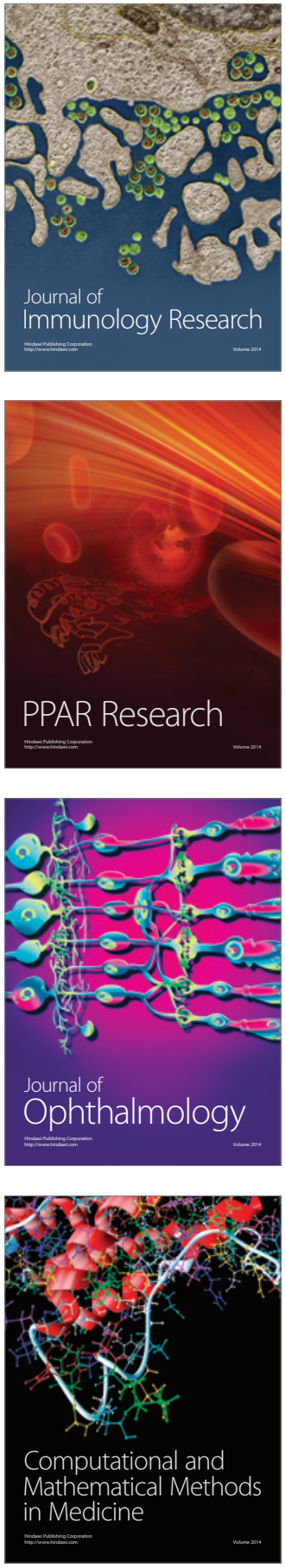

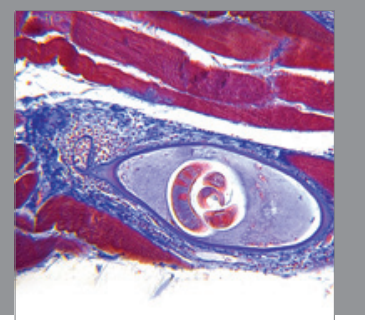

Gastroenterology

Research and Practice
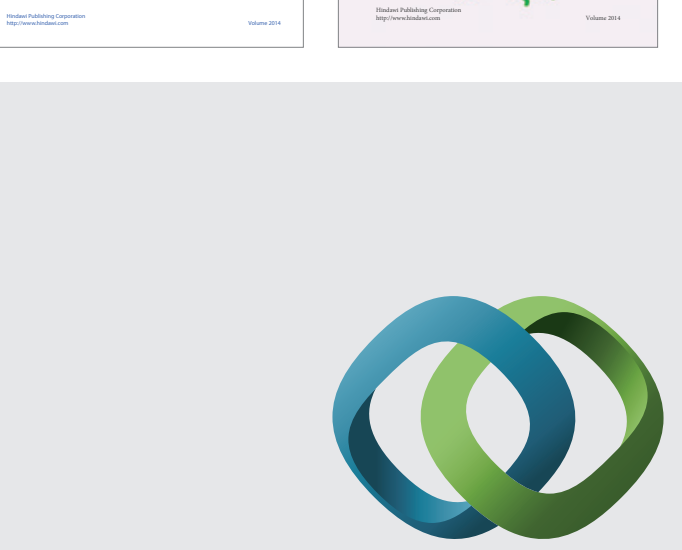

\section{Hindawi}

Submit your manuscripts at

http://www.hindawi.com




Journal of
Diabetes Research

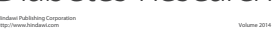

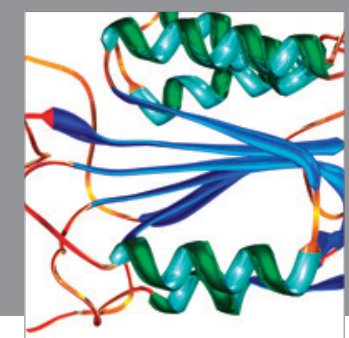

Disease Markers
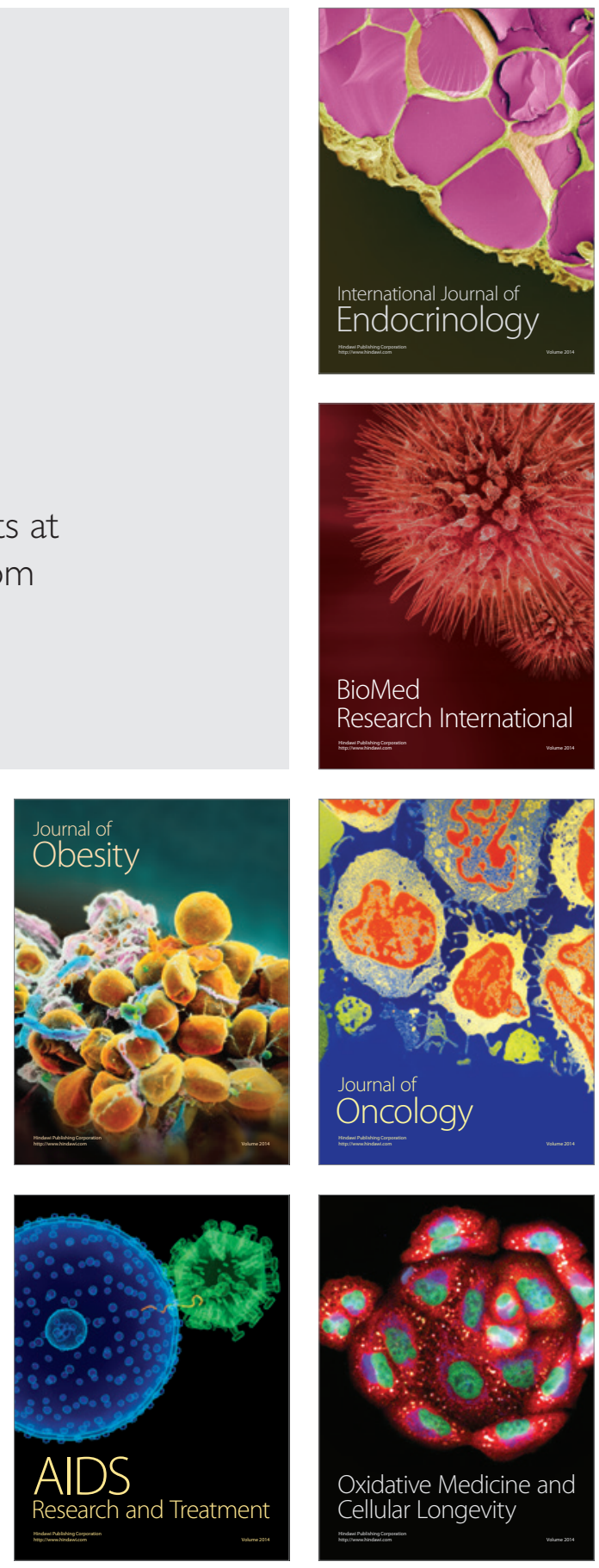